\title{
O impacto da Revolução Cubana sobre a esquerda brasileira (1959-1974)
}

Jean Rodrigues Sales*

\section{A revolução e o Brasil}

A vitória da Revolução Cubana causou grande debate político e intelectual no Brasil.' Para alguns autores, o evento pode ser visto como um divisor de águas na história das esquerdas brasileiras. Marco Aurélio Garcia, ao comentar a trajetória do conceito de revolução no país, vê no reflexo dessa revolução na década de 1960 o marco que delimitaria a passagem de um primeiro momento, marcado pelo impacto da Revolução Russa, para uma segunda fase, identificada pelo surgimento de novas organizações de esquerda influenciadas, em grande parte, pelos valores e pela teoria da revolução cubana. ${ }^{2}$

Em meio a um ambiente de impasse econômico e de rearticulação política, a Revolução Cubana colocaria questões importantes para esquerda comunista brasileira. Ainda segundo Garcia, ela reabriu para a esquerda latino-americana três temas que estavam cristalizados em seu pensamento, tendo recebido até então pouca contestação. $O$ primeiro deles diz respeito à atualidade do socialismo nos países do continente, uma vez que, até os anos 1960, a ideia hegemônica era a de que a revolução seria antiimperialista, antifeudal, nacional e democrática, e na qual a burguesia nacional desempenharia um papel revolucionário. Em segundo lugar, a experiência cubana questionava a ideia que tomara força no comunismo internacional, sobretudo a partir de 1957, sobre as possibilidades da transição pacífica ao socialismo. Por fim, o fato de ter sido dirigida não por um partido comunista, mas sim pelo Movimento 26 de julho, de Fidel Castro, colocava na ordem do dia a discussão sobre o papel da vanguarda revolucionária. ${ }^{3}$

* Doutor em História pela UNICAMP. É professor da graduação e do Programa de Pós-graduação em História da Universidade Federal Rural do Rio de Janeiro (UFRRJ).E-mail: jeanrodrigues5@yahoo.com.br

1 Este artigo apresenta de forma resumida discussões que fizemos em A luta armada contra a ditadura militar. A esquerda brasileira e a influência da Revolução Cubana, São Paulo, Editora da Fundação Perseu Abramo, 2007.

2 Marco Aurélio Garcia, "As esquerdas no Brasil e o conceito de Revolução: trajetórias", en Ângela Araújo (org.), Trabalho, cultura e cidadania, São Paulo, Scritta, 1997, p. 37-47.

$3 \quad$ lbídem. 
As questões suscitadas incidiram diretamente no debate sobre a revolução brasileira nos anos 1960, particularmente em sua perspectiva de esquerda. Assim, o processo de luta político-ideológico aberto no interior das esquerdas brasileiras, que vai ser responsável pelo surgimento dos grupos revolucionários no período, está vinculado, ainda que de maneira nem sempre perceptível, à revolução cubana e seus desdobramentos na América Latina. ${ }^{4}$ Nesse caminho, entendemos a influência da Revolução Cubana como um dos elementos que caracterizaram as definições políticas e ideológicas da esquerda brasileira nos anos 1960. Seja pelo apoio e filiação a muitos aspectos do projeto revolucionário cubano (caso da Nova Esquerda), seja pela crítica à aspiração cubana de irradiar seu modelo revolucionário para o continente (como pode se ver nos casos do Partido Comunista Brasileiro — PCB — e do Partido Comunista do Brasil — PC do B-), seja ainda pela tentava de adequar o foquismo ${ }^{5}$ à realidade brasileira (como foi o caso de muitas organizações da esquerda revolucionária após o golpe militar de 1964). Em todos os casos, a discussão em torno do significado da experiência cubana aparece como um problema fundamental para a definição de sua identidade política.

Ao entender a influência do modelo revolucionário cubano como um dos elementos definidores do projeto político da esquerda comunista na década de 1960 (seja pela afirmação ou negação dessa influência), partimos do pressuposto de que as referências feitas pelas organizações a este modelo não se tratam de mera retórica. Compreendemos que essas referências impregnavam a própria linha política das organizações e, nesse sentido, também a sua prática. Dessa forma, a questão principal é desvendar como se deu historicamente as relações e a influência da Revolução Cubana sobre as organizações comunistas brasileiras, particularmente sobre o seu projeto político. Assim, mesmo considerando os aspectos mais amplos que essa relação possa comportar, a prioridade neste artigo é o entendimento de sua incidência no debate ideológico e na elaboração da linha política das organizações comunistas brasileiras.

Nesse sentido, vale adiantar, acreditamos que essa influência aparece de diversas maneiras, menos como tentativa de cópia mecânica do que aconteceu em Cuba. Nenhuma das organizações em tela, nem mesmo aquelas que são normalmente apontadas como tipicamente foquistas, jamais admitiram que queriam transplantar para o Brasil a experiência cubana. Entretanto, isso não significa dizer que, em muitos aspectos e de formas variadas, tais organizações não tenham se inspirado no processo revolucionário cubano.

Entre as formas que essa influência assumiu, está a de uma inspiração política ampla, servindo para fortalecer bandeiras socialistas e antiburocráticas, sobretudo antes do golpe de 1964. Neste caso, dois exemplos importantes são os da Organização Revolucionária Marxista Política Operária (ORM-POLOP) e da Ação Popular (AP) que, ao surgirem no início dos anos 1960, se apoderaram dessas bandeiras para elaborar os seus programas políticos e, ao mesmo tempo, criticarem o PCB. Duas outras características da influência de Cuba sobre os comunistas brasileiros são as da interferência no debate ideológico das organizações no encaminhamento de suas estratégias políticas e na tentativa dessas organizações adaptarem as ideias centrais do foquismo à realidade política e geográfica brasileira. Houve ainda uma ligação direta com a Revolução Cubana que se deu através dos militantes brasileiros que fizeram treinamento guerrilheiro em Cuba.

A atração pelas ideias cubanas, e pelo foquismo em particular, não se dava ao acaso. Entre outros motivos, deve-se destacar que a teoria do foco guerrilheiro partia do pressuposto de que as condições objetivas estavam prontas para o desencadeamento do processo revolucionário nos países da América Latina e que, portanto, conforme os ensinamentos marxistas, faltariam apenas as condições subjetivas. Estas, por sua vez, poderiam ser criadas pela ação dos guerrilheiros. Além disso, ele subordinava o fator político ao fator militar, fazia uma crítica ácida ao burocratismo e à corrupção que tomara conta de muitos partidos comunistas latino-americanos e propunha que o foco guerrilheiro se responsabilizaria pelo início da luta,

4 Jean Rodrigues Sales, A luta armada contra a ditadura militar. A esquerda brasileira e a influência da Revolução Cubana, São Paulo, Editora da Fundação Perseu Abramo, 2007.

5 Para os objetivos deste artigo, amparado nos documentos das organizações comunistas do período, empregamos o termo de forma ampla, como era utilizado entre as esquerdas nos anos 1960, caracterizando, de uma forma geral, movimentos que, influenciados pela Revolução Cubana, acreditavam ser possível fazer uma revolução socialista através de guerrilhas e sem a presença de um partido comunista. Ver a esse respeito, primeiramente, a obra do próprio Régis Debray (Revolução na revolução, São Paulo, Centro Editorial Latino Americano, s/d) e de Che Guevara (A guerra de guerrilhas, São Paulo, Edições Populares, 1981). 
surgindo a partir dele o embrião do partido revolucionário. ${ }^{6}$ Essas ideias, particularmente após o golpe de 64, foram ao encontro de muitas das aspirações da esquerda revolucionária brasileira.

Com essa configuração a Revolução Cubana chegou às esquerdas brasileiras. É certo que a apreciação e as leituras que fariam da revolução em Cuba variaram de acordo com as modificações que passavam a política nacional, os grupos comunistas e a própria política externa cubana. Entretanto, de uma forma geral, havia duas leituras sobre a vitória da revolução em Cuba. Uma "suave", comandada pelo PCB e pelos nacionalistas em geral, "ressaltando as rupturas com o imperialismo e com o latifúndio como plataforma nacional, democrática e popular"; outra radical, dos grupos da esquerda revolucionária, que "colocavam ênfase no caráter socialista que assumiu rapidamente o processo revolucionário cubano e a estratégia armada como caminho de resolução da questão do poder na sociedade".7

Ainda é necessário ressaltar que para o Movimento Estudantil de uma forma geral, e particularmente em suas lideranças, o exemplo cubano mostrava o horizonte da luta armada para aqueles jovens que ingressavam na Nova Esquerda e que não queriam repetir, em sua avaliação, o mesmo erro que o PCB cometera ao não se preparar para uma resposta eficaz ao golpe civil-militar de 1964. Essa questão é importante pelo fato o setor estudantil ter sido, na segunda metade da década de 1960, o grande fornecedor de militantes para as organizações da esquerda revolucionária. Disso decorre a necessidade de considerar que a Revolução Cubana, ao mesmo tempo em que causava discussões no interior das organizações, também influenciava diretamente o setor que mais fornecia militantes para os grupos revolucionários.

\section{Uma revolução, diversas interpretações}

Uma primeira conclusão a que chegamos diz respeito ao relacionamento da ortodoxia comunista brasileira com a Revolução Cubana. Diferente do que se tem visto na historiografia sobre o PCB e o PC do B, pudemos perceber que a questão cubana esteve presente no debate ideológico dos dois partidos no decorrer dos anos 1960. Dessa forma, não se pode reduzir a dimensão internacional do PCB a seu relacionamento com a URSS, nem a do PC do B a seu alinhamento político à China.

No caso do PCB, a Revolução Cubana foi imediatamente saudada como a corporificação no continente da teoria apregoada há décadas pelos comunistas. Ou seja, Cuba teria conhecido uma revolução democrático-burguesa que logo teria passado para fase socialista, processo no qual o Partido Comunista Cubano teria desempenhado um papel fundamental. Essa apreciação do significado do processo revolucionário cubano, que com dificuldade tentava esconder os aspectos heterodoxos da revolução em Cuba, logo foi questionada por setores partidários. Inicialmente de forma sutil, mas logo ganhando força, sobretudo com a crise aberta em suas fileiras após o golpe de 1964.

Com a chegada dos militares ao poder em abril de 1964, amplos setores do PCB responsabilizaram a política partidária pela derrota dos movimentos sociais diante dos militares e passaram a buscar novos caminhos de atuação. Nesse momento, o modelo revolucionário cubano foi visto por muitos militantes como um exemplo que poderia servir ao Brasil, principalmente no que concerne à utilização da luta armada contra a ditadura militar. A discussão que tomou conta do partido levou à saída de centenas de militantes que deram origem a muitas das organizações da Esquerda Revolucionária brasileira, as quais tinham em comum uma clara influência do foquismo na elaboração de seus projetos políticos.

O PC do B, por sua vez, que naquele momento era aliado dos chineses, enxergava na Revolução Cubana um exemplo da falência da política dos partidos comunistas ligados a Moscou. Alegava que os revolucionários cubanos tinham demonstrado

6 Cfr. Jacob Gorender, Combate nas trevas, São Paulo, Ática, 1998, p.89.

7 Emir Sader, "Cuba no Brasil: influências da revolução cubana na esquerda brasileira", en Daniel Aarão Reis Filho, História do marxismo no Brasil, vol. I, Rio de Janeiro, Paz e Terra, 1991, p. 176. 
definitivamente que a revolução não aconteceria na América Latina sem o uso da violência e que a aliança com a burguesia nacional era absolutamente desnecessária. Apesar disso, após o golpe ele também sofreu cisões que tiveram em sua origem as discussões sobre a luta armada contra a ditadura. A cisão sofrida pelo partido, que deu origem ao Partido Comunista do Brasil-Ala Vermelha (PC do B-AV), buscou no ideário cubano a inspiração para a luta armada, ainda que complementada com elementos do maoísmo.

Como podemos perceber, a Revolução Cubana esteve no centro do debate que originou a Nova Esquerda brasileira, na medida em que contribuiu para engrossar a crítica ao modelo tradicional de partido comunista, levando a cisões no PCB e no PC do B. Mas a sua importância não se resume a isso. Ao mesmo tempo em que a influência fazia sentir no interior da esquerda tradicional, ela desempenhava um papel marcante na estruturação de grupos como a AP e ORM-POLOP, os quais tiveram trajetórias independentes do comunismo tradicional.

\section{A Ação Popular}

A Ação Popular foi criada em uma série de três reuniões entre 1962 e 1963, e teve como base principalmente setores da Juventude Universitária Católica (JUC) que se encontravam em Minas Gerais, com figuras significativas como Herbert José de Souza (Betinho) e Vinícius Cardeira Brant. No Rio de Janeiro, com a presença de Aldo Arantes, primeiro membro do grupo jucista a ocupar a presidência da UNE; e na Bahia, a partir da presença Haroldo Lima, Paulo Mendes, entre outros. Além desses estados, houve apoio para a criação da AP em muitos outros lugares, em grande parte pelo respaldo conseguido pela JUC durante a greve do $1 / 3$ e da UNE-Volante.

A primeira reunião aconteceu em São Paulo, no início de 1962, e aprovou um documento intitulado Estatuto Ideológico, que defendia o "socialismo" e a "revolução brasileira". A segunda reunião aconteceu em junho de 1962, em Belo Horizonte, momento em que foi adotado o nome Ação Popular. A terceira aconteceu em fevereiro de 1963, na cidade da Salvador. Esta última reunião se constituiu no I Congresso da AP e reuniu um considerável número de participantes, aprovando seu o Documento-Base, que serviria como programa ideológico para a AP, pelo menos oficialmente, até por volta de $1968 .{ }^{8}$

\section{Socialismo com humanismo}

Chama a atenção no início dos anos 1960 a original proposta política feita pela a AP que tinha como horizonte um socialismo que era diferente do que existia na URSS, e voltava-se para a libertação do homem. Nesse sentido, a proposta de socialismo da AP, anterior à sua adesão ao maoísmo, antecipou, em vários aspectos, muitas discussões que surgiriam nas décadas de setenta e oitenta sobre as possibilidades de um socialismo com democracia no Brasil. Essa ideologia própria, que se propunha diferenciar-se do marxismo e do idealismo, não impedia que a AP se orientasse em busca do socialismo, constituindo-se em um "movimento revolucionário que se propõe a formar quadros que possam participar de uma transformação radical da estrutura da sociedade brasileira em sua passagem do capitalismo para o socialismo." ${ }^{9}$

A perspectiva era de uma revolução socialista, ainda que na análise da sociedade brasileira a AP apontasse a existência de um setor arcaico e feudal no campo, que coexistia com um setor capitalista. Talvez possamos conjecturar que essa opção pela revolução imediatamente socialista esteja ligada ao impacto causado pelo exemplo cubano no continente americano. Do mesmo modo, as ideias oriundas de Cuba, bem como de outras experiências revolucionárias no Terceiro Mundo, talvez tenham levado a organização a não descartar a possibilidade do uso da violência revolucionária. Nas palavras da AP:

8 Haroldo Lima \& Aldo Arantes, História da Ação Popular: da JUC ao PC do B, São Paulo, Alfa-Omega, 1984, pp. 35-36.

9 Marco Aurélio Garcia, "AP, do cristianismo ao marxismo-leninismo", en Em Tempo, São Paulo, 1979. 
não nos cabe antecipar a forma pela qual se dará a concretização desse processo revolucionário. No entanto, pode-se dizer que a história não registra quebra de estruturas sem violência revolucionária gerada por essas mesmas estruturas, que produzem, em última análise, essa consequência. ${ }^{10}$

Ainda no Documento Base, a AP, ao analisar as experiências socialistas até então existentes, destaca a Revolução Cubana como um exemplo da complexidade do "mundo socialista em gestação", que não se confundindo com o bloco "político-militar soviético", podendo comportar experiências e orientações ideológicas distintas. Nesse sentido, não passa despercebido à AP que "a Revolução Cubana teve um princípio empírico e não ideológico. O caráter marxista-leninista da revolução seria firmado a posteriori, apenas em 1961, diante da conjuntura internacional."11 Nos parece perfeitamente possível afirmar que na medida em que a AP ressaltava o caráter original da revolução feita pelos cubanos, ela estava ao mesmo tempo justificando a sua proposta de socialismo, que se pretendia independente tanto da tradição de esquerda brasileira como de correntes comunistas internacionais.

Essas conjecturas, pouco usuais, é verdade, ao tratar da influência cubana ainda antes de 1964 na AP, baseiam-se principalmente na presença das ideias cubanas na sociedade brasileira em geral, e no movimento estudantil universitário em particular, setor a partir do qual originou-se a AP. É o caso, por exemplo, da própria JUC, que foi influenciada pela revolução cubana em seu processo de radicalização política no final dos anos cinquenta e início da década seguinte. ${ }^{12}$

\section{O impacto do golpe e a atração pelo foquismo}

Toda a mobilização popular do início dos anos 1960, que parecia enfim anunciar uma maior democratização do país, desmoronou sob os tanques que saíram dos quartéis no último dia do mês de março de 1964. A derrota do que parece ter sido o maior movimento de massas da história brasileira marcou profundamente os atores que participaram de seus acontecimentos. A culpa recaiu sobre o PCB, então o partido mais importante entre os grupos de esquerda, e que estava profundamente identificado com a política de João Goulart. A partir das discussões sobre os erros cometidos e os novos caminhos a serem trilhados, a esquerda brasileira se dividiu em enorme número de grupos, que caminhariam, em muitos casos, para a luta armada contra a ditadura militar.

No caso da AP, também as discussões feitas após o golpe modificaram sensivelmente a organização, que reavaliaria criticamente suas posições políticas e ideológicas anteriores. A mudança de rumo da AP apareceria em sua prática — parte de sua direção chegou a se articular com Leonel Brizola, então no exílio uruguaio, em sua tentativa de fazer resistência armada ao regime militar ${ }^{13}$ e, principalmente, em suas concepções ideológicas, com a aprovação da Resolução Política de 1965.

Na Resolução, mesmo afirmando a continuidade com as ideias anteriores, passou-se a enfatizar a necessidade da luta armada revolucionária, com nítida influência foquista. Neste caminho, o documento fez uma série de críticas ao Documento Base, como a imprecisão em relação aos objetivos estratégicos e, em consequência, à tática da AP. Segundo a Resolução

o Documento Base encaminhava para o modelo estratégico de infiltração gradual no poder estabelecido e de radicalização progressiva, através das lutas de massa e ideológicas, tudo conduzindo a uma grave crise decisiva do poder, ou seja, a um desfecho revolucionário. Só que, não prevendo para esse desfecho nenhuma saída, sua estratégia conduzia a um impasse, do que já estamos colhendo frutos antecipados com a ditadura militar implantada no país. ${ }^{14}$

10 Daniel Aarão Reis Filho \& Jair ferreira de Sá (orgs.). Imagens da revolução. Documentos políticos das organizações clandestinas de esquerda dos anos 1961-1971, Rio de Janeiro, Marco Zero, 1985, p. 36.

11 Ibídem, p. 38

12 Haroldo Lima \& Aldo Arantes, História da Ação Popular: da JUC ao PC do B, São Paulo, Alfa-Omega, 1984, p. 27.

13 Sobre as articulações de líderes da AP com Brizola no Uruguai ver Herbert José de Souza, "Depoimento", en Pedro Cavalcante \& Jovelino Ramos (orgs.). Memórias do exílio, São Paulo: Livramento, 1978.

14 O documento "Uma política revolucionária para o Brasil (Resolução Política de 1965)" pode ser consultado no Fundo Duarte Pereira Pacheco (FDPP) no Arquivo Edgard Leuenroth (AEL), na UNICAMP. 
As características da Resolução que têm nítida inspiração foquistas são inúmeras, sobretudo no que se refere ao caminho da luta armada para se chegar a "Revolução Socialista de Libertação Nacional", conceito eclético que revela diversas influências e incertezas na elaboração na nova política revolucionária da AP. Um primeiro ponto que deve ser ressaltado é que no balanço da "perspectiva histórica latino-americana" a AP reafirma como objetivo político a "revolução socialista", e afirma como estratégia a "luta insurrecional". ${ }^{15}$

A AP acabou não aderindo completamente ao foquismo, tendo adotado uma perspectiva influenciada pela Revolução Chinesa que acabou levando-a a aderir ao PC do B. Nesse processo, porém, muitos de seus militantes acabaram deixando a organização e vários deles adotado práticas políticas claramente influenciados pelo foquismo.

\section{Organização Revolucionária Marxista - Política Operária (ORM- POLOP)}

Quando o Congresso de fundação foi instalado na cidade de Jundiaí, interior de São Paulo, em 1961, a POLOP contava com cerca de 20 delegados representando aproximadamente 100 militantes oriundos de diversos grupos e setores sociais. Entre seus fundadores estavam membros oriundos da Juventude Socialista, da Guanabara; da Liga Socialista; da Juventude trabalhista, de Minas Gerais; do Partido Socialista Brasileiro (PSB), e de muitos militantes independentes. As suas influências, segundo Marco Aurélio Garcia (1979), vinham principalmente de Talheiner, dirigente do Partido Comunista Alemão nos anos 20 e Bukharin, bolchevique morto por Stalin nos anos 30. Havia ainda uma herança do Partido Obrero de Unificação Marxista (POUM), que atuou na Guerra Civil Espanhola e era forte crítico do stalinismo.

O que unia essa diversidade de tendências, segundo Teothônio dos Santos, um dos seus líderes e fundadores, era, antes de tudo, a crítica à linha política adotada pelo PCB em 1958, que propunha uma aliança com a burguesia para completar as tarefas democrático-burguesas no país. Ao contrário disso, os jovens intelectuais da POLOP partiam de uma análise segundo a qual o capitalismo estava plenamente desenvolvido no país e a luta contra os elementos pré-capitalistas da sociedade, como a estrutura agrária, "contra o imperialismo e pela implantação da democracia não poderiam se dar nos marcos de um capitalismo democrático, tal como o PCB e o ISEB defendiam." ${ }^{16}$ Nesse caminho, a revolução socialista aparecia como necessidade inadiável para resolução do problema da classe trabalhadora. A estratégia revolucionária, por sua vez, retomava claramente o modelo bolchevique de revolução e propunha a insurreição de massas liderada pela classe operária como caminho para se chegar ao socialismo. Ruy Mauro Marini, um dos fundadores da organização, resume a proposta inicial da POLOP:

Nossa concepção estratégica geral era a de que a evolução seria violenta, com a tomada do poder concretizada por uma insurreição proletária urbana. A base do poder armado seria constituída pelas camadas inferiores das forças armadas burguesas, fracionadas horizontalmente no quadro de aguçamento da crise institucional ${ }^{17}$

Para a implementação de tal programa, a POLOP apontaria a necessidade da criação de um verdadeiro partido operário que aplicasse construtivamente o marxismo, uma vez que a "velha esquerda" se mostrara incapaz de fazê-lo. O novo partido deveria surgir da nova geração revolucionária, que demonstrava a sua existência em atuações na crise política, nas universidades, nas fábricas e nas ruas, tomando as iniciativas "de luta anti-imperialistas, que propaga as ideias da revolução cubana e que defende os precários direitos democráticos quando ameaçados por golpes de direita". ${ }^{18}$

15 Ibídem, p. 33.

16 Dênis de Moraes, A esquerda e o golpe de 1964, Rio de Janeiro, Espaço e Tempo, 1988, 342.

17 Leogevildo Pereira Lean, Política Operária: a quebra do monopólio político teórico e ideológico do reformismo na esquerda brasileira, Dissertação de Mestrado, Niterói, UFF, 1992, p. 32.

18 "O nome e o programa", en Política Operária, n 1, janeiro de 1962. (Trata-se do primeiro número do jornal da organização, que circulou como boletim antes da formação oficial do grupo, depois como jornal mensal, a depois como revista. Circularia ainda como jornal semanal de janeiro a abril de 1964 e, clandestinamente, até 1984. Cfr. Leogevildo Pereira Leal, Política Operária: a quebra do monopólio político teórico e ideológico do reformismo na esquerda brasileira, Dissertação de Mestrado, Niterói, UFF, 1992, p. 35. 


\section{Cuba: anti-imperialismo e revolução}

Um dos fundadores da POLOP aponta o caso cubano como um marco histórico que cerca a origem do grupo. ${ }^{19}$ Além disso, desde antes de seu surgimento, seus principais ideólogos já refletiam sobre os caminhos da revolução em Cuba estavam preocupados em entender o processo revolucionário cubano e o papel de Cuba no cenário político latino-americano e da guerra fria. ${ }^{20}$ Neste caminho, entre novembro e dezembro de 1960, Ruy Mauro Marini escreveu uma série de três artigos para o jornal O Metropolitano sobre a Revolução Cubana, ressaltando que Cuba teria demonstrado que "anti-imperialismo e revolução social nada mais são que aspectos de uma só realidade".21

O documento de convocação de seu Congresso de fundação afirmava que o "exemplo de Cuba indica hoje os rumos da revolução na América Latina". Além disso, se o anti-imperialismo latente no hemisfério havia encontrado o seu auge na Guatemala, em Cuba ele reapareceu de forma muito mais radical, na medida em que foi um movimento que nasceu da classe média, mas estava tomando medidas "que ultrapassavam os métodos tradicionais da pequena-burguesia latino-americana e, no campo externo, aceita ajuda material do mudo socialista para sobreviver."22 Enfim, no primeiro número do jornal Política operária, a organização afirmava que Cuba preocupava o imperialismo porque tinha destruído algumas teses correntes, como a da onipotência ianque e do desenvolvimento burguês, "pois mostrou que o subdesenvolvimento econômico ainda não implica em subdesenvolvimento político". Além disso, ela continuava a dar aos trabalhadores aulas práticas de luta de classes. ${ }^{23}$

No que diz respeito aos aspectos mais polêmicos da estratégia revolucionária cubana, como a utilização da guerra de guerrilhas, a POLOP os trataria com bastante cautela. Em abril de 1962, foi publicado um artigo no jornal Política operária, no qual ao mesmo tempo em que se analisa o livro recém lançado no Brasil de Che Guevara, Guerra de guerrilhas, nos serve também para verificar o posicionamento da organização sobre a guerrilha e foquismo no período que antecede o golpe militar de 1964.

O artigo começa lembrando que a Revolução Cubana, entre outras coisas, trouxe ensinamentos sobre a estratégia e a tática da insurreição no continente americano, embora seu aproveitamento ainda estivesse apenas no início. Entre as principais contribuições da experiência cubana à dinâmica dos movimentos sociais, estão aquelas apontadas por Guevara em seu escrito: 1) As forças populares podem ganhar uma guerra contra o exército regular; 2) Nem sempre se faz necessário esperar que se deem todas as condições para a revolução, o foco insurrecional pode criá-las; 3) Na América subdesenvolvida, o terreno da luta armada deve ser fundamentalmente o campo. ${ }^{24}$

As contribuições da Revolução Cubana apresentadas acima, sempre segundo a POLOP, deveriam ser examinadas com cautela para evitar interpretações equivocadas, uma vez que o próprio Che Guevara advertia que em países onde existissem governos representativos não se poderia iniciar a luta guerrilheira. Além disso, devia-se lembrar das condições cubanas no momento em que eclodiu a revolução: Cuba não tinha passado por um processo de industrialização; toda a sua economia girava em torno do açúcar; as classes dominantes foram incapazes de minimizar os problemas sociais através de reformas, recorrendo à ditadura de Batista. Além disso, por viver praticamente do açúcar, a guerrilha pôde desestabilizar o país ao atacar a produção de cana-de-açúcar e, no final, o ditador Batista foi abandonado por todas as classes.25

Para a POLOP, as condições apontadas acima dificilmente se repetiriam, "em futuro próximo", na América Latina. Tal impossibilidade, segundo a organização, se devia, em primeiro lugar, à criação de fatos consumados pela revolução cubana, o que seria facilmente detectado em outro movimento e qualquer revolução nos países da América Central levaria a intervenção

19 Ibídem, p. 129.

20 Ver a esse respeito os artigos: "Kruchtchiov e a defesa da revolução cubana", en Política Operária. Boletim n 4, 1962 e "Coexistência pacífica e guerra de classe", en Política Operária, Boletim n 5, 1962.

21 Ruy Mauro Marini, "A verdadeira face da revolução", en 0 metropolitano, 25/12/1960.

22 Apud Leogevildo Pereira Leal, Política Operária: a quebra do monopólio político teórico e ideológico do reformismo na esquerda brasileira, Dissertação de Mestrado, Niterói, UFF, 1992, p. 158.

23 "Terceiro aniversário da evolução cubana", en Política Operária, n 1, janeiro de 1962. Sobre o apoio da POLOP a Revolução Cubana, ver ainda no mesmo jornal o artigo "Moção de solidariedade a Cuba de Fidel Castro".

24 "A propósito da 'Guerra de guerrilhas"', en Política Operária, n², abril de 1962

25 lbídem 
dos EUA. Enfim, a POLOP lembra que em muitos países do continente as burguesias estariam se dispondo a resolver o problema agrário para eliminar a tensão revolucionária, o que retiraria nestes países o papel preponderante que a guerrilha teve em Cuba. ${ }^{26}$

A POLOP concluiria a sua análise sobre a guerra de guerrilha afirmando que sociedades mais complexas eram mais sensíveis à conjuntura econômica capitalista, não sendo preponderantes apenas as questões estritamente nacionais. Lembraria ainda que em países como Brasil, Argentina e Chile, as possibilidades legais, às quais se refere Guevara, não estavam esgotadas. Deste modo, a revolução em Cuba, apesar da importante contribuição, não bastaria para enfrentar os problemas da luta revolucionária em países mais desenvolvidos, sendo, portanto, essencial considerar os aspectos nacionais para não cair no erro da transplantação mecânica da experiência cubana. ${ }^{27}$

\section{O impacto do golpe: insurreição urbana e foco revolucionário}

"Até o golpe, éramos contra o foco guerrilheiro. Com o golpe o assumimos teórica e praticamente como propagandístico e catalisador". Assim resume Ruy Mauro Marini a aproximação da POLOP das ideias foquistas. Para ele, o propósito era erguer uma bandeira que fosse capaz de "reagrupar forças do movimento operário em dispersão e catalisar o descontentamento com o golpe, inclusive no interior das forças armadas para depois fracioná-las horizontalmente." Ainda para Marini, essa concepção do foco se mantinha dentro da "estratégia geral da insurreição".28

A explicação de Marini resume a avaliação que a POLOP fez após o golpe de 1964 de que era possível articular a sua proposta de insurreição urbana com a ideia do foco revolucionário. Entretanto, a nosso ver, tanto em sua prática, quanto em suas elaborações teóricas, a organização vai se aproximando cada vez mais da ideia clássica do foquismo e, por consequência, se afastando de sua estratégia original.

A aproximação e aceitação por parte da POLOP da teoria clássica do foco, ou seja, de que um grupo de militantes, ao iniciar a guerrilha pode impulsionar o processo revolucionário, se deu no decorrer de 1967. Podemos perceber essa gradual adesão ao foquismo, em primeiro lugar, na mudança da tônica sobre a questão em sua imprensa periódica, e, em seguida, em seus próprios documentos programáticos. Nesse caminho, a organização, em abril, ao comentar o episódio que envolveu a chamada "guerrilha do Caparaó", afirmava a sua "simpatia" pela decisão dos participantes de derrubar a ditadura, e "desencanto" pela falta "de maior decisão e firmeza dos primeiros lutadores presos". ${ }^{29}$ Em maio, apontava que "quando a voz de Cuba se estende novamente pelo continente, as guerrilhas obtêm vitórias na Bolívia, Venezuela e Guatemala, que ainda no Brasil a experiência de Caparaó mostra que é possível enfrentar as forças da reação", sendo necessário estender a agitação e organização das massas contra a ditadura..$^{30} \mathrm{Em}$ julho, ressaltava o papel fundamental da OLAS, principalmente por desmascarar os revisionistas e impulsionar a luta revolucionária. ${ }^{31}$

No mesmo caminho, em setembro de 1967 a POLOP realizou seu IV Congresso, no qual foi apresentado o documento Programa socialista para o Brasil, sintetizando discussões que estavam em curso desde o golpe de 1964. Um dos temas fundamentais do documento era exatamente o papel da luta armada, em sua forma de guerra de guerrilha, na estratégia revolucionária da organização. Aqui, a POLOP demonstraria definitivamente que pretendia unir insurreição de massas e foquismo em sua luta política, o que viria, certamente, com uma forte influência da experiência cubana. O último parágrafo

26 Ibídem.

27 Ibídem.

28 Apud Leogevildo Pereira Leal, Política Operária: a quebra do monopólio político teórico e ideológico do reformismo na esquerda brasileira, Dissertação de Mestrado, Niterói, UFF, 1992, p. 214.

29 "A guerrilha no Brasil", en Política Operária, (Informe Nacional n 59), 8 de abril de 1967. (Coleção D.A. R. F. Dossiê 20, caixa 11. doc. 14. APER). Rio de Janeiro).

30 "Ação da esquerda", en Política Operária, (Informe Nacional n 61), 21 de maio de 1967. (Coleção D.A. R. F. Dossiê 20, caixa 11. doc. 15. APERJ. Rio de Janeiro).

31 "A revolução latino-americana e a conferência da OLAS", Política Operária, (Informe Nacional n 65) 22 de julho de 1967. (Coleção D.A. R. F. Dossiê 20, caixa 11. doc. 19. APERJ. Rio de Janeiro). 
do documento não deixa dúvida sobre o papel desempenhado pelas ideias cubanas nas discussões e na elaboração do projeto político da POLOP:

\begin{abstract}
A primeira tarefa política do foco guerrilheiro há de ser, desta maneira, a de colocar claramente no cenário político do país uma nova liderança, uma alternativa revolucionária ao poder das dominantes. $O$ fato consumado do foco de guerrilha elevará o nível da luta, apressará a unificação das forças da esquerda revolucionária e a continuação do partido revolucionário da classe operária. Da instalação do foco até a insurreição do proletariado da cidade, haverá um caminho prolongado, mas será um caminho só, com um objetivo traçado: a Revolução dos trabalhadores brasileiros no caminho do socialismo. Será essa a nossa contribuição decisiva para a construção de uma nova sociedade no mundo, liberta para sempre da exploração do homem pelo homem. Ao mobilizar os operários sob a bandeira da luta de classes ouvir-se-á, também, dos rincões deste país, o brado da guerra: PROLETARIOS DE TODOS OS PAISES, UNI-VOS! ${ }^{32}$
\end{abstract}

A definição da POLOP a respeito da luta armada foi um dos temas mais controversos das discussões de seu IV Congresso. Enquanto alguns achavam insuficientes os preparativos efetivos para o desencadeamento da guerrilha, outras defendiam a necessidade do trabalho junto aos sindicatos, abandonando o projeto guerrilheiro. No final, por motivos diferentes, um número grande de militantes era contrário à adoção do Programa socialista para o Brasil. Contra o projeto, na interpretação de Eder Sader, havia uma proposta de libertação nacional, por parte do grupo do Rio de Janeiro e outra voltada para uma revolução democrático-burguesa, oriunda de militantes de Minas Gerais. Um terceiro projeto teria sido apresentado pelo grupo de São Paulo, "recém ganho pelo foquismo", que apresentou um conjunto de teses "que se limitavam a transcrever as posições da OLAS (realizada em agosto), logrando com isso aglutinar as outras tendências de oposição". ${ }^{33}$

O resultado da votação final não podia ser mais revelador do enfraquecimento do poder da direção da POLOP. Os defensores do Programa Socialista para o Brasil venceram por 16 votos a 14. A estreita margem foi o primeiro passo para as cisões que a organização viria a sofrer nos meses seguintes. Neste caso, a influência do foquismo no debate interno é inegável, o que pode ser percebido pela própria discussão congressual e, principalmente, no caminho que os militantes descontentes seguiram após saírem da organização. De fato, excetuando uma parte do núcleo dirigente que manteve a defesa do Programa Socialista para o Brasil, a maioria dos militantes criou organizações que propunham a luta armada como tarefa imediata. Por exemplo, membros egressos da POLOP estão presentes na fundação de duas organizações que estão entre as mais representativas do foquismo no Brasil. São os casos do Comando de Libertação Nacional (COLINA), formado basicamente pelos militantes oriundos de Minas Gerais e da Vanguarda Popular Revolucionária (VPR), criada por militantes paulistas.

\title{
As Ligas Camponesas e os campos de treinamento guerrilheiro
}

Usualmente quando se trata da influência cubana sobre as esquerdas brasileiras, se pensa imediatamente na luta armada contra o regime militar na segunda metade dos anos 1960 e início dos anos 1970. A predominância dessa temática se justifica pela vinculação patente de muitos grupos da Esquerda Revolucionária com os cubanos. Entretanto, vale lembrar que as ideias cubanas já circulavam e influenciavam as esquerdas brasileiras desde antes do golpe. Além das questões que já tratamos acima, como nos casos da AP e da POLOP, a história das Ligas Camponesas pode ser tomada como um exemplo da forma de influência das ideias cubanas sobre setores da esquerda brasileira antes de 1964.

Inicialmente, as Ligas Camponesas, que surgiram no interior de Pernambuco por volta de 1955, tinham como objetivo principal promover a assistência entre os seus associados e lutar pela promoção de uma reforma agrária no país. A mudança

\footnotetext{
32 "Programa socialista para o Brasil, setembro de 1967", en Daniel Aarão Reis Filho \& Jair Ferreira de Sá (orgs.). Imagens da revolução. Documentos políticos das organizações clandestinas de esquerda dos anos 1961-1971, Rio de Janeiro, Marco Zero, 1985, p. 116.
} 
em suas propostas pode ser identificada entre 1961 e 1962, quando muitos de seus membros fizeram viagens a Cuba. Os dirigentes das Ligas criaram vínculos importantes com Fidel Castro, o que possibilitou ao grupo brasileiro se tornar pioneiro no envio de militantes para fazer treinamento guerrilheiro na ilha de Fidel.

As trajetórias de Francisco Julião e Clodomir de Morais são os maiores exemplos da influência da Revolução Cubana nas Ligas Camponesas. Julião, como principal representante do movimento na segunda metade dos anos cinquenta, defendia um projeto de reformas que se adequava às leis vigentes no país. Porém, entre 1960 e 1961 percebemos claramente a mudança de suas propostas, nas quais a experiência cubana, principalmente no que diz respeito ao papel dos camponeses e da questão agrária no processo revolucionário, aparecem como elementos fundamentais de seu novo posicionamento político.

Em 1961, veio ao Rio de Janeiro Luis Felipe Carneal, membro do Comitê Central do Parido Popular Socialista de Cuba. A seu pedido, foi até Recife e convidou as Ligas Camponesas a enviar uma delegação para as comemorações do 26 de julho e para a fundação da Associação Nacional de Agricultores Cubanos (ANAC). As Ligas enviaram cerca de 80 membros, entre os quais estavam os que participaram do treinamento guerrilheiro em Cuba. Além destes, também foram na viagem dirigentes do PCB, elevando o número da delegação para cerca de 115 pessoas. ${ }^{34}$ Seja pelo fato de Fidel Castro acreditar que as Ligas eram o movimento que mais chance tinha de fazer uma revolução no Brasil, seja pelas demonstrações que seus membros deram na tentativa de invasão de Playa Giron, quando entregaram uma lista de cinco mil camponeses brasileiros dispostos a pegarem em armas para defender Cuba, o fato é que, naquele momento, a organização de Francisco Julião recebia um tratamento diferenciado no país de Fidel Castro.

Segundo Clodomir Santos de Morais, o seu grupo foi o primeiro entre os brasileiros a treinar em Cuba. Mesmo entre os países da América Latina, aparentemente somente os venezuelanos haviam estado lá anteriormente. Até mesmo por ser o primeiro, o treinamento não aconteceu da forma que se esperava. Em primeiro lugar, para o caso brasileiro, não haveria consenso entre Fidel Castro e Che Guevara para se dar treinamento aos militantes. Guevara se mostrara contrário em função das relações cordiais que o governo brasileiro mantinha com Cuba. Fidel, por sua vez, teve que usar o seu prestígio pessoal para que o treinamento acontecesse. Em segundo lugar, não havia, naquele momento, qualquer preparação, programa ou estrutura prévia para que o curso acontecesse adequadamente, tendo sido feito de forma improvisada. ${ }^{35}$

Após este "curso" realizado em Cuba, ainda outros militantes voltaram àquele país, mas apenas para apreender alguns aspectos específicos úteis à guerrilha, como foi caso de Pedro Porfírio, que lá foi para aprender a fabricar bombas de plástico. Com essa viagem, o grupo decidiu que o treinamento guerrilheiro deveria ser feito no Brasil e, com ajuda de setores cubanos, voltaram e deram início imediato dos chamados campos de treinamento das Ligas Camponesas.

\section{O dispositivo militar e os campos de treinamento guerrilheiro.}

Segundo a versão de Clodomir de Morais, ${ }^{36}$ a motivação para a criação dos "focos de resistência guerrilheira" veio com a invasão da Baia dos Porcos, em abril de 1961. A ideia era a de que o exemplo da tentativa de invasão de Cuba pelos EUA colocava em perigo qualquer governo amigo dos cubanos no continente, inclusive o de João Goulart. Além da ameaça externa, era de se considerar que em sete anos o Brasil havia passado por pelo menos sete tentativas de golpes contra o

34 Entrevista de Clodomir Santos de Morais ao autor.

35 Ibídem. Sobre a falta de estrutura para a realização dos cursos, vale lembrar que ainda em 1965, quando membros do MNR foram fazer treinamento em Cuba não havia uma estrutura preparada, e os militantes brasileiros acabaram ajudando a construir a escola. Pela leitura do livro de Rollemberg, somente os militantes que foram posteriormente a Cuba (da ALN, do MR-8 e da VPR) encontraram uma estrutura mais adequada, ainda que em muitos aspectos precária. Cfr. Denise Rollemberg, $\mathbf{O}$ apoio de Cuba à luta armada no Brasil: o treinamento guerrilheiro, Rio de Janeiro, MAUAD, 2001.

36 A versão de Clodomir Morais sobre a questão dos campos de treinamento guerrilheiro pode ser vista principalmente em um pequeno texto que escreveu, provavelmente no final dos anos sessenta, sobre a história das Ligas. A primeira edição é de 1970 e foi publicada em inglês (Cfr. Clodomir Santos de MOrais. Peasant leagues in Brazil, en Rodolfo Stavenhhagen, Agrarian problems and peasant movements in Latin

America, New York, Anchor Books, 1970); a segunda edição foi publicada em Honduras, em espanhol, em 1976. Somente em 1997 o texto foi traduzido para o português (Cfr. Clodomir Santos de Morais, História das Ligas Camponesas do Brasil, Brasília, Edições lattermund, 1997). Utilizamos também a entrevista que ele nos concedeu e, ainda, a entrevista concedida a Dênis Moraes (Cfr. Dênis de Moraes, A esquerda e o golpe de 1964, Rio de Janeiro, Espaço e Tempo, 1988). 
regime representativo. Por fim, havia os enormes suprimentos de carabinas e fuzis automáticos (25 mil armas) proporcionados pelo governador Adhemar de Barros, do estado de São Paulo, para que os latifundiários se defendessem da Reforma Agrária. Todos esses elementos fizeram com que os dirigentes das Ligas abandonassem o plano de organização camponesa a longo prazo e passassem a preparar a resistência guerrilheira.

A concepção geral do dispositivo militar ficou sob a responsabilidade de Clodomir Santos de Morais, que tinha o papel ainda de ligação entre o "setor armado" e o setor "de massas" ou "político" das Ligas camponesas, sendo que este último era liderado por Francisco Julião. ${ }^{37}$ Pela própria natureza das atividades, a atuação do setor armado era feita de forma absolutamente clandestina e autônoma em relação ao restante do movimento. O que não significa dizer, como fizeram alguns autores, que o setor político, ou mais especificamente Francisco Julião, não soubesse da existência dos preparativos para o treinamento guerrilheiro. Na verdade, por motivos de segurança, as atividades eram compartimentadas e, neste caso, Julião era responsável pelo proselitismo político junto às massas, não lhe cabendo participar de decisões que diziam respeito à guerrilha. ${ }^{38}$

No que diz respeito ao treinamento guerrilheiro propriamente dito, quase nada foi feito. O que conseguiram, de fato, foi o que tinham realmente experiência e prática política: a organização dos camponeses em associações, a exemplo das Ligas Camponesas. Como admite o próprio Clodomir Santos de Morais:

Os homens das Ligas que fundaram os campos de treinamento de guerrilhas, desprovidos de preparação adequada, pouco puderam transmitir da arte militar aos seus companheiros. Em um ano, à espera de uma voz de comando que nunca chegou, os futuros guerrilheiros tiveram que enfrentar todas as naturais consequências de um longo período de isolamento; da falta de atividade prometida; da ausência de um programa armado bem definido e, ainda mais, da falta de uma sólida unidade dos organismos dirigentes, fatores estes que destroem moral, política, ideológica e organicamente a qualquer grupo de combatentes. ${ }^{39}$

Foi nesta situação que, em novembro de 1962, o grupo de Dianópolis viu chegar durante a noite um grupo do exército na fazenda, causando a fuga dos militantes que lá se encontravam. As versões sobre a dissolução dos campos são controversas. Para alguns, como o próprio Clodomir, as autoridades já sabiam o que se passava na região e vinham a tempo vigiando as atividades do grupo. Já no livro autobiográfico de Flávio Tavares, que nos anos sessenta teve ligações políticas com Leonel Brizola e com a chamada Guerrilha do Caparaó, é relatado que a descoberta teria se dado completamente ao acaso. Em sua versão, o tenente responsável foi alertado dos constantes carregamentos de "geladeiras" que chegavam as fazendas, e cogitava que se tratasse de armas que estariam sendo contrabandeadas pelos latifundiários de Goiás, que se preparavam para se opor aos planos de reforma agrária de Jango. Ao chegar na fazenda, o que o exército encontrou

foi algumas armas e muitas, muitas bandeiras cubanas, retratos e textos de discursos de Fidel Castro e do deputado pernambucano Francisco Julião, manuais de instrução de combatente, além de planos de implantação de outros futuros focos de sabotagem e uma minuciosa descrição dos fundos financeiros enviados por Cuba para montar o acampamento e todo o esquema de sublevação armada das Ligas Camponesas noutros pontos do país. ${ }^{40}$

O caso dos campos de treinamento guerrilheiro trouxe à tona um tema que acarretaria problemas para a diplomacia cubana e brasileira. Entre os materiais apreendidos pelo exército em Dianópolis, estavam documentos que mostravam claras ligações entre Cuba e os campos de treinamento guerrilheiro ainda no período do governo João Goulart. Os papeis apareceram quando um diplomata cubano veio ao Brasil e recebeu os tais documentos do governo brasileiro, que fizera um gesto conciliatório diante das graves implicações da participação cubana em um plano de guerrilha contra um país que mantinha relações diplomáticas com a ilha de Fidel Casto. De volta ao seu país, o ministro cubano morreu em um desastre de avião

37 Sobre a autonomia do setor armado, ver: Clodomir Santos de Morais, História das Ligas Camponesas do Brasil, Brasília, Edições lattermund, 1997; Fernando Antônio Azevedo, As Ligas camponesas, Rio de Janeiro, Paz e Terra, 1982 e Joseph Page, A revolução que nunca houve: 0 nordeste do Brasil -1955-1964, Rio de Janeiro, Record, 1972. 
perto de Lima, no Peru. Os documentos que o cubano transportava, entretanto, caíram nas mãos das autoridades policiais, e foram divulgados pela imprensa, inclusive no Brasil.41

Entre outras informações, os documentos assinados por líderes do campo de treinamento guerrilheiro, Tarzan de Castro e Carlos Montarroyo, demonstravam uma série de divergências destes com a liderança de Clodomir Morais. Por exemplo, um problema que incomodava seria o fato de Clodomir enviar para fazer treinamento em Cuba "boêmios da cidade", enquanto deixava de lado "companheiros que já estavam nos dispositivos militares há quase dez meses". Além disso, denunciava ao governo cubano que o dinheiro que este enviava ao Brasil estava sendo aplicado de forma "irresponsável e mentirosa" pelo esquema guerrilheiro. ${ }^{42}$

Outro tema polêmico que envolve a queda dos campos de treinamento é o da implicação do governo cubano no apoio financeiro à guerrilha no Brasil, ainda mais com a apreensão dos documentos citados acima. O que está fora de dúvida é que houve apoio do governo cubano, na medida em que propiciou os cursos de treinamento em seu país. Em relação aos recursos financeiros, segundo Clodomir de Morais, vieram não exatamente do governo de Cuba, mas da Associação Nacional dos Agricultores Cubanos, com a qual as Ligas mantiveram contato desde 1961, quando participaram de sua inauguração. A ANAC teria se constituído em importante fonte financeira para as Ligas, que recebiam ainda recursos da Federação Sindical Mundial e de outras organizações de trabalhadores de países socialistas. ${ }^{43}$

Em seu livro sobre o treinamento guerrilheiro em Cuba, Denise Rollemberg demonstra que enquanto havia um setor do Estado cubano que estava sintonizado com a realidade das derrotas das tentativas de implantação de focos, e a redefinição do apoio às guerrilhas no continente, havia outro setor afinado com o mito da vanguarda, que eram os que estavam envolvidos com a exportação da revolução. ${ }^{44}$ Neste sentido, nos parece plausível a versão de Clodomir sobre a origem dos recursos financeiros das Ligas, que viriam da ANAC e não do governo cubano. De qualquer forma, é difícil imaginar que se pudesse agir em Cuba sem que o aparato do Estado não fizesse pelo menos vistas grossas às operações financeiras envolvendo o Brasil.

Por fim, vale registrar que, para além das divergências da cúpula do movimento, havia um evidente sentimento favorável a Cuba e a guerrilha na base camponesa, o que não significa dizer que existia, de fato, o objetivo de se fazer uma revolução através de uma guerrilha, tal como como acontecera em Cuba. Exemplar nesse sentido é o caso da militante Elizabeth Teixeira, esposa de João Pedro Teixeira, líder camponês assassinado, que relatou o desejo de muitos camponeses no Nordeste brasileiro em pegar em armas. A explicação para esse posicionamento dos camponeses passa certamente pelas campanhas em favor de Cuba, pela adoção de palavras de ordem pró-cubanas em manifestações das Ligas de Sapé, como "Viva a Cuba!, Viva A Fidel!, Viva as Ligas Camponesas!", (acrescentaríamos aqui os discursos de Julião sobre a revolução cubana), pela visita de Célia Guevara, mãe de Che Guevara, à Sapé, ${ }^{45}$ pela difícil luta a favor da reforma agrária diante da crescente violência praticada pelos latifundiários, que tiraram a vida de seu próprio marido e tentaram matar seu filho. Diante dessa situação de radicalização das lutas no campo, segundo Elizabeth, ela e seus companheiros defendiam aspectos do que que havia acontecido em Cuba: apoiavam uma guerrilha que que realizasse uma reforma agrária no país. ${ }^{46}$ Em outras palavras, para setores dos camponeses brasileiros, o exemplo cubano ganhava relevo sobretudo no que dizia respeito à luta pela terra e na defesa contra a violência dos latifundiários.

41 Ibídem, p. 78.

42 Os documentos foram publicados sob o título "Agentes de Fidel relatam atividades e pedem recursos para fazer subversão", en Correio da manhã, 29/01/1963.

43 Entrevista de Clodomir Santos de Morais ao autor.

44 Denise Rollemberg, 0 apoio de Cuba à luta armada no Brasil: o treinamento guerrilheiro, Rio de Janeiro, MAUAD, 2001, p. 18.

45 Sobre a visita, ver: "D. Célia Guevara fala aos camponeses de Sapé", en Novos Rumos, 16 a 22/06/1961.

46 Entrevista de Elizabeth Teixeira ao autor. 


\section{O golpe de 1964 e a eclosão da luta armada}

O golpe civil-militar de 1964 representou um momento de inflexão para as esquerdas brasileiras, sobretudo para os comunistas, causando um amplo debate entre as organizações sobre as causas da derrota do movimento popular e, principalmente, o caminho que deveria ser seguido na nova situação política aberta com a chegada dos generais ao poder. Nesse momento, é de se destacar que praticamente todas as organizações comunistas que existiam no período anterior a 1964 sofreram cisões a partir de discussões em torno do tema da definição de uma nova estratégia política.

Assim, o PCB sofreu diversas cisões que deram origem a grupos como a Ação Libertadora Nacional (ALN), Partido Comunista Brasileiro Revolucionário (PCBR), Movimento Revolucionário 8 de Outubro (MR-8), entre outras. Do PC do B saíram militantes que criaram o Partido Comunista do Brasil -Ala Vermelha (PC do B-AV) e o Partido Comunista Revolucionário (PCR). A AP teve pelo menos duas divisões importantes, a primeira deu origem ao Partido Revolucionário dos Trabalhadores (PRT) e a segunda a Ação Popular Marxista Leninista (AP-ML). Da ORM-POLOP, por sua vez, saíram militantes que criaram o Comando de Libertação Nacional (COLINA), a Vanguarda Popular Revolucionária (VPR) e o Partido Operário Comunista (POC).

Nas cisões e na definição do novo caminho de luta diante da instauração da ditadura militar, a temática da Revolução Cubana ganhou destaque. Pode-se afirmar que todos os grupos que pegaram em armas contra a ditadura militar na segunda metade dos anos 1960 dialogaram com as ideias cubanas. Nesse diálogo, alguns se aproximavam mais das ideias que emergiam de Cuba, outros menos, mas todos trataram do tema na definição de sua estratégia política, principalmente no que diz respeito ao caminho armado. Além disso, é perceptível que os mesmos grupos que, antes de 1964, simpatizavam com a Revolução Cubana, mas não propunham que seu modelo fosse implementado no Brasil, após o golpe passam a enxergar na luta armada um caminho viável para derrotar a guerrilha recém implantada.

\section{Conclusões}

A Revolução Cubana representou um momento importante na história da América Latina. Talvez nem o mais otimista militante de esquerda, nem o mais pessimista dos conservadores do continente imaginassem que a ditadura de Fulgencio Batista seria destruída da forma como foi, e tampouco que o grupo 26 de Julho, liderado por Fidel Castro, chegaria e permaneceria no poder. Menos ainda se esperava que o regime cubano assumiria um caráter socialista e não seria esmagado pelos vizinhos norte-americanos. Foi um evento espetacular que ganhou espaço no centro das discussões geopolíticas da guerra fria e atraiu o interesse dos mais variados setores sociais.

No Brasil não foi diferente. Muitos contra, outros a favor, mas toda a imprensa e a crônica política estavam empenhadas em entender o que se passava em Cuba e quais consequências poderiam haver para o Brasil. Comitês de Solidariedades foram criados para apoiar Cuba diante das ameaças dos EUA. Muitos livros foram publicados no período para explicar e entender o processo revolucionário cubano. A intelectualidade progressista discutia os caminhos da Revolução Cubana e da chamada Revolução Brasileira nos conturbados anos 1960.

No entanto, certamente foi entre as esquerdas que o tema da Revolução Cubana ganhou maior destaque. O que se pretendeu neste artigo foi contribuir para o entendimento da história do comunismo no Brasil através da compreensão do papel que o impacto causado pela experiência cubana teve no debate ideológico e nas formulações políticas das organizações comunistas no país nos anos sessenta e setenta.

Nesse sentido, entendemos que a Revolução Cubana foi um dos principais temas que estiveram em pauta na definição da estratégia política das organizações comunistas no decorrer dos anos 1960 e 1970. Certamente não foi uma relação estanque e sofreu mudanças decorrentes dos processos políticos cubano e brasileiro, além do próprio debate entre as organizações. A mais visível dessas modificações aconteceu com o golpe de 1964, quando houve uma profunda discussão entre os comunistas, que fizeram mudanças substanciais em suas propostas e práticas políticas. Nesse momento, também a percepção do significado e dos ensinamentos da Revolução Cubana se modificaram. 
Uma primeira conclusão diz respeito ao relacionamento da ortodoxia comunista brasileira com a Revolução Cubana. Diferente do que se tem visto na historiografia sobre o PCB e o PC do B, pudemos perceber que a questão cubana esteve presente no debate ideológico dos dois partidos no decorrer dos anos sessenta. Dessa forma, não se pode reduzir a dimensão internacional do PCB a seu relacionamento com a URSS, nem a do PC do B a seu alinhamento político à China.

No caso do PCB, a revolução cubana foi imediatamente saudada como a corporificação no continente da teoria apregoada há décadas pelos comunistas. Para o partido, a América Latina teria conhecido uma revolução democrático-burguesa que logo teria passado para fase socialista, processo no qual o Partido Comunista Cubano teria desempenhado um papel fundamental. Essa apreciação do significado do processo revolucionário cubano, que com dificuldade tentava esconder os aspectos heterodoxos da revolução cubana, logo foi questionado por setores partidários. Inicialmente de forma sutil, mas logo ganhando grande força, sobretudo após o golpe de 1964.

O PC do B, por sua vez, via na Revolução Cubana um exemplo da falência da política dos partidos comunistas ligados a Moscou, principalmente no que diz respeito ao uso da violência e a aliança com a burguesia nacional. Apesar disso, após o golpe ele também sofreu cisões que tiveram em sua origem as discussões sobre a luta armada contra a ditadura. A cisão sofrida pelo partido, que deu origem ao Partido Comunista do Brasil- Ala Vermelha (PC do B-AV), foi buscar no ideário cubano a inspiração para a luta armada, ainda que complementada com elementos do maoísmo.

Além dos debates no $P C B$ e $P C$ do $B$, a questão cubana teve um papel importante na estruturação de grupos como a AP e ORM-POLOP. No primeiro caso, o exemplo cubano serviu para justificar a proposta heterodoxa de socialismo feita pela $A P$, que procurava se distanciar do socialismo real, propondo um socialismo com humanismo. No caso da ORM-POLOP, a revolução cubana serviu para fortalecer a sua proposta de uma revolução imediatamente socialista, que contrastava com a bandeira da revolução por etapas empunhada pelo PCB e PC do B. Após o golpe, entretanto, principalmente a ORM-POLOP, sofreria cisões que tinham na origem a atração exercida pelo foquismo.

Após o golpe de 1964, a influência da Revolução Cubana sobre a esquerda revolucionária a partir dos casos da ALN, PCBR, MR-8, PC do B-AV e COLINA. A ideia central que procuramos destacar foi a de que as concepções cubanas desempenharam um papel importante na elaboração do projeto político da esquerda revolucionária. Uns mais do que outros, mas todos os grupos dessa esquerda dialogaram com as propostas de Che Guevara e Regis Debray. É perceptível como esses grupos procuraram, sem sucesso, adaptar o foquismo à realidade brasileira.

Por fim, destacamos o caso das Ligas Camponesas, que mesmo não sendo uma organização comunista sofreu forte influência da Revolução Cubana. A relação com Cuba fez o grupo sofrer uma verdadeira mutação política, abandonando a bandeira da reforma agrária dentro da lei e passando a se aproximar de uma proposta de transformação da estrutura agrária do país. O agrupamento foi responsável ainda pela implantação de campos de treinamento guerrilheiro no interior de Goiás com clara inspiração na luta guerrilheira empreendida pelos cubanos.

A partir das discussões que fizemos no decorrer do artigo, a conclusão geral é que dificilmente seria possível tratar da história das organizações comunistas brasileiras nos anos sessenta sem se destacar o papel desempenhado pela influência da Revolução Cubana. Pouco importa se de fato os grupos analisados, por mais que tenham se aproximado das ideias cubanas, tenham conseguido implantar uma guerrilha rural. O importante é que os comunistas brasileiros, seja através da crítica ou da adesão, discutiram intensamente o projeto revolucionário cubano e procuraram, de formas diferenciadas, utilizar as contribuições oriundas de Cuba para a elaboração de seus projetos políticos nos anos sessenta e setenta. 


\section{Resumen}

El objetivo principal de este texto es analizar la influencia de la Revolución Cubana sobre las izquierdas comunistas brasileñas en el período de 1959 a 1974. Se trata de entender en qué medida las ideas del foquismo y la guerra de guerrillas influenciaron el debate ideológico de los comunistas brasileños y cuáles fueron sus desdoblamientos para sus formulaciones teóricas y su práctica política. La conclusión general es que diversos aspectos del ideario revolucionario cubano estuvieron presentes en el surgimiento de la izquierda revolucionaria brasileña, en el debate respecto de la lucha armada contra la dictadura militar y en la adopción de la bandera del socialismo por una parte de esa izquierda.

\section{Palabras Clave}

Revolución Cubana; Guerra de guerrillas; Comunismo brasileño

\section{Abstract}

The main objective of the present thesis is to analyze the relationships between the Brazilian communist leftist movements and the Cuban revolution between 1959 and 1974. We aim at understanding how far the ideas of the foquismo and the guerilla war influenced the ideological debate of the Brazilian communists and the consequences for its theoretical formulations and the political practice. The general conclusion is that the Cuban revolutionary process was mainly present in the debate on the definition of the armed resistance to the military dictatorship and the adoption of socialism by a part of that leftist movement.

\section{Key-words}

Cuban Revolution; Guerrilla Warfare; Brazilian Communism. 